\title{
Supply Chain Collaboration: A Game-Theoretic Approach to Profit Allocation
}

\author{
Borja Ponte(iD), Isabel Fernández(D), Rafael Rosillo(iD, José Parreño(iD, Nazario Garcíaii \\ University of Oviedo (Spain) \\ ponteborja@uniovi.es, ifa@uniovi.es, rosillo@uniovi.es,parreno@uniovi.es,ngarciaf@uniovi.es
}

Received: July 2016

Accepted: October 2016

\section{Abstract:}

Purpose: This paper aims to develop a theoretical framework for profit allocation, as a mechanism for aligning incentives, in collaborative supply chains.

Design/methodology/approach: The issue of profit distribution is approached from a gametheoretic perspective. We use the nucleolus concept. The framework is illustrated through a numerical example based on the Beer Game scenario.

Findings: The nucleolus offers a powerful perspective to tackle this problem, as it takes into consideration the bargaining power of the different echelons. We show that this framework outperforms classical alternatives.

Research limitations/implications: The allocation of the overall supply chain profit is analyzed from a static perspective. Considering the dynamic nature of the problem would be an interesting next step.

Practical implications: We provide evidence of drawbacks derived from classical solutions to the profit allocation problem. Real-world collaborative supply chains need of robust mechanisms like the one tackled in this work to align incentives from the various actors. 
Originality/value: Adopting an efficient collaborative solution is a major challenge for supply chains, since it is a wide and complex process that requires an appropriate scheme. Within this framework, profit allocation is essential.

Keywords: beer distribution game, game theory, incentive alignment, profit allocation, supply chain collaboration

\section{Introduction}

In the current global business scene, a premium has been placed upon collaboration as a core source of gaining competitive advantages in supply chains. The strategic importance of supply chain collaboration has turned this concept into a fruitful research area over the last two decades (Puche, Ponte, Costas, Pino \& de la Fuente, 2016).

As a result, collaborative practices based on information sharing have been successfully implemented in real supply chains, such as Efficient Consumer Response (ECR) (Wood, 1993), Vendor Managed Inventory (VMI) (Waller, Johnson \& Davis, 1999) and Collaborative Planning, Forecasting and Replenishment (CPFR) (Fliedner, 2003).

Nonetheless, information sharing (the access to private data in all partners' systems) must be understood as only one feature of supply chain collaboration. In the same line as Simatupang and Sridharan (2005), we define a feature as an area of collaborative effort that has a positive impact on performance. These authors also highlight process integration (which refers to the design of an efficient supply chain that deliver product to the customers at the right time) and decision synchronization (which includes both joint decisionmaking mechanisms and the reallocation of decisions rights in order to synchronize the planning and execution levels) as key additional features within a successful collaborative scheme. In addition, the use of overall performance indicators (a systemic scorecard, that is, the use of metrics that quantify the performance of the supply chain as a whole) is indispensable to guide the collaborative efforts towards a successful global optimization -in contrast to non-collaborative supply chains, which are based on local optimization.

In the analysis by Simatupang and Sridharan (2005), these four features (namely, information sharing, process integration, decision synchronization, and systemic scorecard) have shown to be necessary but not sufficient. A last feature emerges to make collaboration viable in the long term: incentive alignment. The various supply chain nodes must be motivated to act in a manner consistent with the overall strategic goals (Ponte, Costas, Puche, De la Fuente \& Pino, 2016); otherwise, they may behave opportunistically 
and this situation would lead collaboration to failure (Fawcett, McCarter, Fawcett, Webb \& Magnan, 2015).

In this sense, supply chain collaboration can be understood as a pyramid. Its competitive advantage is based on process integration (Level 2). This integration, which should be guided through a systemic scorecard, must be built on synchronized decisions and shared information, which can be understood as the enablers (Level 1). The whole collaborative structure is supported by incentive alignment (Level 0): the different supply chain actors cannot feel that they have anything to gain by deviating from the overall strategy of the system. This pyramidal notion, aimed at making viable and taking full advantage of supply chain collaboration, is illustrated by Figure 1.

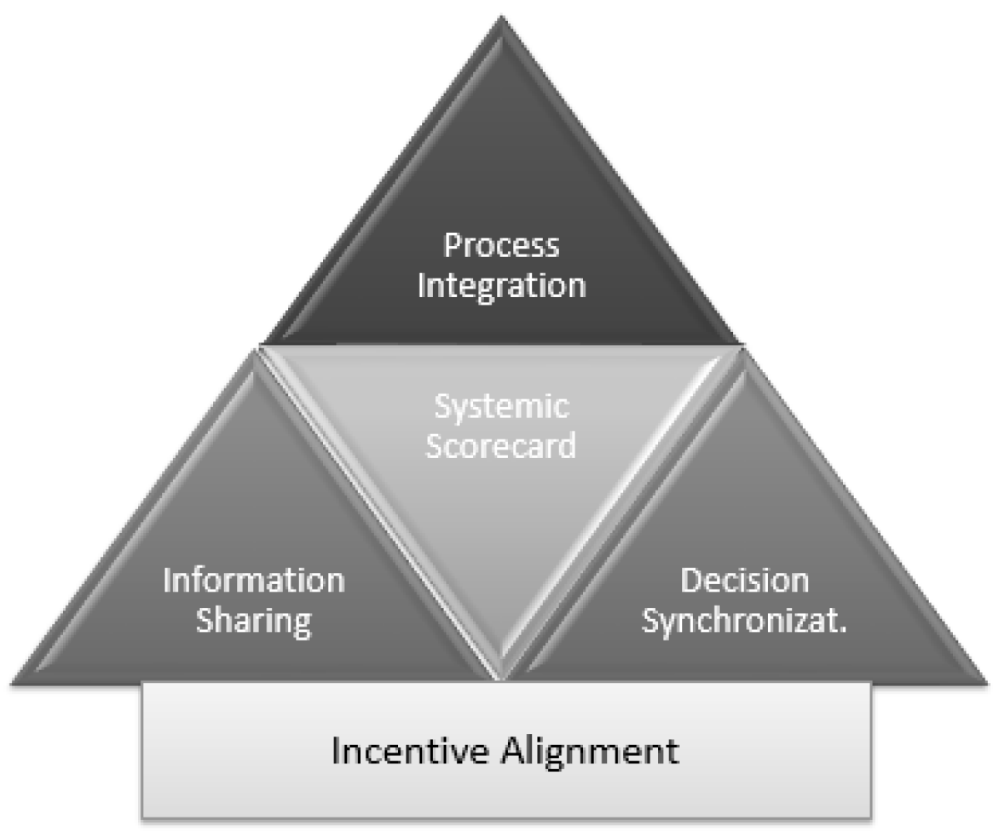

Figure 1. The pyramid of supply chain collaboration, adapted from Simatupang and Sridharan (2005)

In general terms, incentive alignment refers to profit allocation (Simatupang \& Sridharan, 2007). The overall profit achieved through optimizing globally the supply chain -which (by definition of collaboration) will be higher than the sum of the individual profits achieved through local optimizationmust be distributed among the various participants. Simatupang and Sridharan (2008) points out that the allocation must be based on two principles: (1) compensation fairness, which refers to an equitable sharing; and (2) self-enforcing, which ensures that the nodes keep aligned with the overall goal of improving total profits. 
Under these circumstances (and following the core concepts on supply chain collaboration introduced in Section 1), this paper uses game-theoretic concepts to propose a robust framework for aligning incentives in collaborative supply chains. Section 2 contains three stages. First, we present the nomenclature of the problem. Second, we define the conditions that the distribution of the overall profit must verify. Third, we propose the allocation of the overall profit among the various supply chain nodes through a mechanism based on the nucleolus concept (Schmeidler, 1969). Hereinafter, Section 3 illustrates its application by means of a numerical example developed on the Beer Game supply chain, in which we compare several solutions for profit allocation. Finally (Section 4), we conclude and we draw some avenues for future work on this issue.

\section{A Game-Theoretic Framework for Allocating the Surplus}

In this section, we first describe the key variables involved in the problem of profit allocation in collaborative supply chains as well as their mathematical notation based on cooperative game theory. Secondly, we discuss three conditions that must be verified by viable profit distributions. Finally, we propose a specific solution to this problem built on the nucleolus concept.

\subsection{Mathematical Notation}

Let $N$ denote the set of supply chain members; $N=\{1, \ldots, n\}$, where $n \geq 2$ refers to the number of them.

Let $v(C)$ be a characteristic function that assigns to each coalition $C$ the net profit earned by its members as a result of their joint efforts. In this sense, a coalition $C$ represent several nodes $(C \subseteq N)$ who participate within the same collaborative solution. Hence, note that: (1) $v(i)$ represents the net profit that obtains the node $i$ by acting alone (i.e., when node $i$ seeks local optimization); and (2) $v(N)$ represents the overall net profit obtained by the supply chain when all nodes participate in the collaborative process (i.e., when they seek global optimization). As common in the literature on game theory, we will simplify $v(\{a, b, c\})$ to $v(a b c)$ when we refer to the net profit obtained by the coalition $C=\{a, b, c\}$ formed by nodes $a, b$, and $c$.

Regarding the net profit generated by the various coalitions that may arise in the supply chain, we assume the following properties, which fit perfectly with the definition of supply chain collaboration: 
1. Monotonicity, which means that enlarging a coalition within the supply chain always increases its the net profit; i.e., $v\left(C^{\prime}\right) \leq v(C) \forall C^{\prime} \subseteq C$.

2. Supperaditivity, which means that the net profit of any coalition is larger than the sum of smaller coalitions within the previous one; i.e., $v(C) \geq v\left(C^{\prime}\right)+v\left(C^{\prime \prime}\right) \forall C^{\prime}, C^{\prime \prime} \subseteq C, C^{\prime} \cap C^{\prime \prime}=\varnothing$.

Note that the previous properties imply that the maximum net profit will be achieved in the supply chain when all nodes involve in collaboration; i.e., $v(N)=\max \{v(C)\}$.

\subsection{Problem Statement and Conditions of the Distribution}

Under this scenario, the key question is how the overall net profit generated by each collaborative solution must be distributed among among its constituent supply chain nodes. Let $x(i, C), i \in C \subseteq N$, be the decision variables in this problem. They refer to the net profit allocated to the supply chain actor $i$ when he/she collaborates within the coalition $C$.

From this point on, we define those allocations that verify the following three necessary conditions as viable profit allocations.

1. Efficiency, which means that the overall net profit generated by the coalition has been distributed among all its members; i.e., $v(C)=\sum_{i \in C} \chi(i, C)$.

2. Individual rationality, which means that each node gets more by collaborating than what he/she would get by acting alone; i.e., $v(i)<x(i, C) \forall i$.

3. Coalition rationality, which means that if a new member incorporates to a specific coalition, the former supply chain members get more than what they earned in the previous coalition; i.e. $v(C \cup\{i\})-x(i, C)>v(C)$.

Note that individual rationality is an essential condition, as it means that the coalition has a positive (financial) impact on every node involved in it. If this condition is not verified, at least one node will have a strong motive for breaking away from the coalition. Coalition rationality expresses a similar idea: if it is not verified, a group of nodes will have a strong motivation for breaking away from the coalition and create together an independent one. 


\subsection{The Nucleolus Solution}

The nucleolus (Schmeidler, 1969) is a solution concept in cooperative game theory that assigns a unique distribution of the overall surplus generated by the coalition. The nucleolus solution is based on quantifying the happiness of the coalition $C^{\prime}$ in relation to a predefined allocation within a larger coalition $C$. This can be expressed as the difference between how much the nodes of the coalition $C^{\prime}$ are earning in the larger coalition $C$ and how much they would be earning by breaking away the large coalition and collaborating among themselves, i.e.,

$$
h(C, C)=\sum_{i \in C} x(i, C)-v\left(C^{\prime}\right) .
$$

Note that if $h\left(C^{\prime}, C\right)$ is high, the coalition $C^{\prime}$ will not have a strong incentive for breaking away from the larger coalition $C$. From this point, the nucleolus solution aims to maximize the happiness of the most unhappy coalition. Hence, it can stated as,

$$
\max (\min \{h(C, C)\}) .
$$

In this sense, the nucleolus solution takes into consideration the bargaining power of the different supply chain members (Saad, Han, Debbah, Hjorungnes \& Basar, 2009). That is, the larger the net profit of a node $i$, the stronger its bargaining power in the different coalitions where this node participates. Similarly, the larger the net profit of a specific coalition $C^{\prime}$, the stronger its bargaining power of the net profit generated by a larger coalition $C$.

Some years ago, Nagarajan and Sošić (2008) highlighted that "despite its nice properties, the nucleolus is yet to find its application in the supply chain management literature". They only found two papers that applied this concept to the supply chain (Hartman \& Dror, 1996; Leng \& Parlar, 2009), which showed that this solution could be a useful mechanism to allocate the cost savings derived from cooperation. Other recent works in this same scenario should be highlighted, such as Lozano, Moreno, Adenso-Díaz and Algaba (2013). The main difference of our approach lies in the fact that we focus on profit distribution as a more robust mechanism for the alignment of incentives throughout the supply chain. 


\section{A Numerical Example Based on the Beer Game Supply Chain}

The Beer Game role-playing exercise, which aims to teach the main principles of supply chain management, has been used in countless management courses since it was developed at the MIT (Jarmain, 1963). Its scenario is defined by a single-product serial supply chain, composed of four main actors: factory, distributor, wholesaler, and retailer (e.g. Ponte, Pino \& de la Fuente, 2014). This simple supply chain has proven to be very effective in helping practitioners and researchers to understand the causal relationships between decision-making and supply chain performance (Goodwin \& Franklin, 1994). For this reason, the Beer Game scenario, which is schematically shown in Figure 2, has been widely studied in the literature. We will employ it to illustrate the framework proposed for profit allocation in the supply chain.

Thus, we have a supply chain with $n=4$ echelons. In this section, we will use the following notation: $i=1$ for the factory; $i=2$ for the distributor; $i=3$ for the wholesaler; and $i=4$ for the retailer.

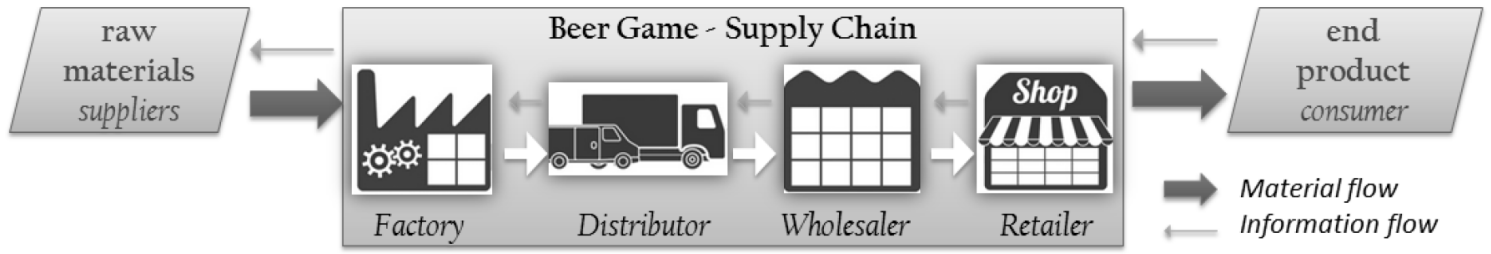

Figure 2. Overview of the Beer Game supply chain, standing out the two main flows

\subsection{Assumptions}

The Beer Game scenario dramatically amplifies the variability of the orders and inventories as they move up the supply chain; see e.g. Sterman (1989). This phenomenon, the so-called Bullwhip Effect, is a harmful source of inefficiencies within the supply chain, which significantly decreases the overall performance (Wang \& Disney, 2016). By way of example, we assume that the supply chain net profit is $\$ 1,000$ under a non-collaborative approach; i.e., $v(1)+v(2)+v(3)+v(4)=\$ 1,000$. As previously mentioned, the Bullwhip Effect specially damages the upper echelons, so we will consider the following profits: $v(4)=\$ 400$ for the retailer, $v(3)=\$ 300$ for the wholesaler, $v(2)=\$ 200$ for the distributor, and $v(1)$ $=\$ 100$ for the factory.

The Beer Game also illustrates that the overall performance of the system -both in operational and in economic terms-dramatically improves when collaborative practices are introduced in the system; see e.g. Costas, Ponte, de la Fuente, Pino and Puche (2015). For example, we will assume that the supply chain net 
profit is $\$ 1,500$ under a fully collaborative approach; $v(N)=v(1234)=\$ 1,500$. Under this approach aimed at local optimization, the key question is how the decision makers should allocate the surplus generated by collaboration among the four nodes.

We will also need as baseline information the impact evaluation of the various nodes breaking away from the collaboration. Since the retailer observes the customer demand (hence sharing information would be incomplete without it), we will assume this is a key node within the collaborative framework. For this reason, we consider for example that if this echelon does not involve in collaboration, the supply chain would only make $\$ 1,200$; i.e. $v(123)+v(4)=\$ 1,200$. Similarly, the factory elaborates the product, so its participation in the collaborative process is also essential. Hence, let's assume that, if this node breaks away, the system would make $\$ 1,400$; i.e., $v(234)+v(\{4\})=\$ 1,150$. In a similar vein, we have considered that if the wholesaler leaves the collaborative solution, it will significantly impact on the supply chain since this node manages the distribution flow. We consider that the profit would also be $\$ 1,400$ in this case; $v(124)+v(3)=\$ 1,150$. On the contrary, the supply chain net profit has been assumed to be less sensitive to the participation of the distributor: the system would make $\$ 1,400$ if this node does not involve in collaboration; i.e., $v(134)+v(2)=\$ 1,450$.

Note that from the previous information, we could easily calculate the net profit obtained from the four possible 3-node coalitions in the supply chain. This information is shown in Table 1, together with the different results obtained in the 2-node coalitions. These net profits, which are also starting information of this problem, have been set taking into consideration the previously explained notion of the weights of the different nodes.

\begin{tabular}{|c|c|c|c|}
\hline No coalitions & 2-node coalitions & 3-node coalitions & 4-node coalitions \\
\hline$v(1)=100$ & $v(12)=400$ & $v(123)=800$ & $v(1234)=1,500$ \\
\hline$v(2)=200$ & $v(13)=450$ & $v(124)=850$ & \\
\hline$v(3)=300$ & $v(14)=600$ & $v(134)=1,250$ & \\
\hline$v(4)=400$ & $v(23)=550$ & $v(234)=1,050$ & \\
\hline & $v(24)=650$ & & \\
\hline & $v(34)=750$ & & \\
\hline
\end{tabular}

Table 1. Net profit for the different possible coalitions in the supply chain 


\subsection{Classical Mechanisms for Net Profit Allocation}

Before analyzing the proposed game-theoretical solutions, we will analyze two traditional alternatives. In the first one, we will consider an equitable distribution of the overall surplus generated by the collaboration (Method 1), which is

$$
\text { Surplus }=v(1234)-[v(1)+v(2)+v(3)+v(4)]=\$ 500 .
$$

Under this distribution criteria, the solution to the allocation problem would imply an increase of each node's profit in the non-collaborative context by $\$ 500 / 4=\$ 125$. Hence, we would have that $x(i, N)=$ $v(i)+\$ 125$, that is:

$$
\begin{aligned}
& x(1, N)=\$ 225 \\
& x(2, N)=\$ 325 \\
& x(3, N)=\$ 425 \\
& x(4, N)=\$ 525
\end{aligned}
$$

Another basic solution, although more advanced than the previous one, would be to take into account the differences between the supply chain nodes, and consequently to consider how much each node was earning in the non-collaborative context. From this point, the surplus is distributed proportionally (Method 2). Therefore, $x(i, N)=v(i)+$ Surplus $\cdot k_{i}$, where $k_{i}=v(i) / \sum_{a=\{1,2,3,4\}} v(a)$. This situation would lead to the following distribution:

$$
\begin{aligned}
& x(1, N)=\$ 150 \\
& x(2, N)=\$ 300 \\
& x(3, N)=\$ 450 \\
& x(4, N)=\$ 600
\end{aligned}
$$

Note that while the first method makes equal the increase in absolute terms of the net profit of the different supply chain nodes $(\$ 125)$, the second method makes equal the increase in relative terms $(50 \%)$.

At a first glance, these solutions could seem acceptable. In fact, a discussion with several groups of students revealed that the proportional distribution of the surplus was understood as the most intuitive solution to the allocation problem. Nonetheless, a reminder of the previously defined concept of happiness for each possible coalition, made come to surface its significant drawbacks. 


\begin{tabular}{|c|r|r|}
\hline$h(C, N)$ & Method 1 & Method 2 \\
\hline$h(1, N)$ & 125 & 50 \\
\hline$h(2, N)$ & 125 & 100 \\
\hline$h(3, N)$ & 125 & 150 \\
\hline$h(4, N)$ & 125 & 200 \\
\hline$h(12, N)$ & 150 & 50 \\
\hline$h(13, N)$ & 200 & 150 \\
\hline$h(14, N)$ & 150 & 150 \\
\hline$h(23, N)$ & 200 & 200 \\
\hline$h(24, N)$ & 200 & 250 \\
\hline$h(34, N)$ & 200 & 300 \\
\hline$h(123, N)$ & 175 & 100 \\
\hline$h(124, N)$ & 225 & 200 \\
\hline$h(134, N)$ & -75 & -50 \\
\hline$h(234, N)$ & 225 & 300 \\
\hline
\end{tabular}

Table 2. Happiness of each possible coalition in Methods 1 and 2

Table 2 shows that not only the happiness of the different coalitions will vary significantly, but also that a specific coalition, the one formed by nodes 1,3 , and 4 (factory, wholesaler, and retailer) will fell unhappy with both scenarios. Note that the sum of the net profit of nodes 1, 3, and 4 would be $\$ 1,175$ when using Method 1 and $\$ 1,200$ with Method 2, while $v(134)=\$ 1,250$. This means that coalition rationality does not apply: these three nodes will not be interested in node 2 (distributor) joining to the collaborative process since their allocation suffers as a result of the node 2 presence in the coalition. Seeing from another perspective, this supply chain member is capturing more profit than what he/she contributes to the collaborative supply chain with.

\subsection{The Nucleolus Solution for Distributing the Net Profit}

The nucleolus solution implies analyzing the allocation issue as an optimization problem aimed at maximizing the happiness of the most unhappy coalition (Method 3). The only constraint to be considered is that the sum of the individual net profits must equal the overall net profit of the system $(\$ 1,500)$, i.e., the efficiency property. From this optimization problem applied to the previously defined scenario, we obtain the following solutions:

$$
\begin{gathered}
x(1, N)=\$ 225 \\
x(2, N)=\$ 225 \\
x(3, N)=\$ 410.5 \\
x(4, N)=\$ 639.5
\end{gathered}
$$


Table 3 shows the happiness of the four nodes operating individually $(b(i, N))$ in the first four rows. Since all these values are positive, it means that individual rationality apply. That is to say, they gain by participating in the collaborative solution. From this point on, Table 3 shows the happiness of the possible coalitions in the system (except obviously the fully collaborative solution) in the last ten rows. These values are also positive. Hence, unlike Methods 1 and 2, coalition rationality does apply, and there is not any coalition in the system that would be interested in breaking away from the overall collaborative supply chain. However, note that we have highlighted (in bold) the minimum happiness in the system, which corresponds to node 2 (distributor) and to the coalition formed by nodes 1, 3, and 4 .

\begin{tabular}{|c|r|}
\hline$h(C, \boldsymbol{N})$ & Nucleolus solution \\
\hline$h(1, \boldsymbol{N})$ & 125 \\
\hline $\boldsymbol{h ( 2 , \boldsymbol { N } )}$ & $\mathbf{2 5}$ \\
\hline$h(3, \boldsymbol{N})$ & 110.5 \\
\hline$h(4, \boldsymbol{N})$ & 239.5 \\
\hline$h(12, \boldsymbol{N})$ & 50 \\
\hline$h(13, \boldsymbol{N})$ & 185.5 \\
\hline$h(14, \boldsymbol{N})$ & 264.5 \\
\hline$h(23, \boldsymbol{N})$ & 85.5 \\
\hline$h(24, \boldsymbol{N})$ & 214.5 \\
\hline$h(34, \boldsymbol{N})$ & 300 \\
\hline$h(123, \boldsymbol{N})$ & 60.5 \\
\hline$h(124, \boldsymbol{N})$ & 239.5 \\
\hline $\boldsymbol{h ( 1 3 4 , \boldsymbol { N } )}$ & $\mathbf{2 5}$ \\
\hline$h(234, \boldsymbol{N})$ & 225 \\
\hline
\end{tabular}

Table 3. Happiness of each possible coalition in the nucleolus solution (Method 3)

Figure 3 displays the allocation for the three solutions. In a similar vein, Table 4 compares the three allocation methods that we have analyzed in terms of: (a) the absolute increase of the nodes' net profit; (b) the relative increase of the nodes' net profit; and (c) the percentage each node gathers from the surplus generated by collaboration. 


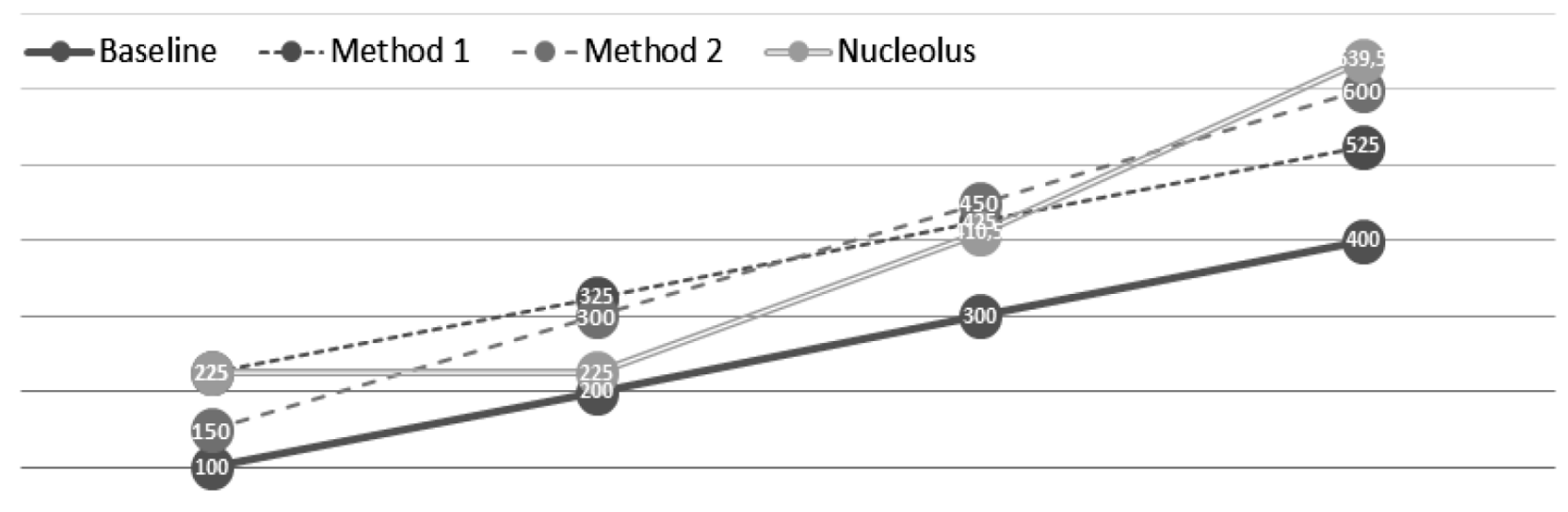

\begin{tabular}{lll}
\hline FACTORY & DISTRIBUTOR & WHOLESALER
\end{tabular}

Figure 3. The nucleolus solution versus traditional methods for profit allocation

\begin{tabular}{|c|c|c|c|c|c|}
\hline Method & Node & Net profit & $\Delta \mathrm{abs}$ & $\Delta$ rel & $k_{i}$ \\
\hline \multirow{4}{*}{ Method 1} & Factory & 225 & 125 & $125.00 \%$ & $25.00 \%$ \\
\hline & Distributor & 325 & 125 & $62.50 \%$ & $25.00 \%$ \\
\hline & Wholesaler & 425 & 125 & $41.67 \%$ & $25.00 \%$ \\
\hline & Retailer & 525 & 125 & $31.25 \%$ & $25.00 \%$ \\
\hline \multirow{4}{*}{ Method 2} & Factory & 150 & 50 & $50.00 \%$ & $10.00 \%$ \\
\hline & Distributor & 300 & 100 & $50.00 \%$ & $20.00 \%$ \\
\hline & Wholesaler & 450 & 150 & $50.00 \%$ & $30.00 \%$ \\
\hline & Retailer & 600 & 200 & $50.00 \%$ & $40.00 \%$ \\
\hline \multirow{4}{*}{ Nucleolus } & Factory & 225 & 125 & $125.00 \%$ & $25.00 \%$ \\
\hline & Distributor & 225 & 25 & $12.50 \%$ & $5.00 \%$ \\
\hline & Wholesaler & 410.5 & 110.5 & $36.84 \%$ & $22.10 \%$ \\
\hline & Retailer & 639.5 & 239.5 & $59.87 \%$ & $47.90 \%$ \\
\hline
\end{tabular}

Table 4. Net profit increase in absolute $(\Delta a b s)$ and relative $(\Delta r e l)$ terms for the various allocation methods, as well as the percentage $\left(k_{i}\right)$ each node gathers from the surplus.

While Methods 1 and 2 would not be acceptable for some nodes as we have seen before, the nucleolus solution -derived from applying this game-theoretic concept- offers a powerful framework from which to approach this problem. It should be underlined that the nucleolus solution is based on taking into consideration the bargaining power of the different nodes. For this reason, the distributor will gather only a small part of the surplus generated by collaboration (5\%)-he/she was capturing $25 \%$ of the surplus in Method 1 and 20\% in Method 2, which was not right for the other nodes whose contribution to the collaborative solution is much more significant. Hence, the distributor will be forced to accept this situation. In this sense, the supply chain actors who benefit the most from the nucleolus solution are 
those whose presence in the collaborative solution is essential -namely, the factory and the retaileraccording to the scenario that has been previously defined.

\section{Conclusions}

Supply chain collaboration can be interpreted as two or more firms working together to achieve higher profits than those that can be obtained by acting alone (Simatupang \& Sridharan, 2002). Within the collaborative scheme aimed at optimizing the system in its entirety, information sharing and decision synchronization must be understood as enablers, while the competitive advantages are built on process integration.

These features are necessary, but not sufficient: incentive alignment also plays a key role. The collaborative solution would not be viable if some of the supply chain members had incentives to break away. In this sense, game theory provides managers with a powerful approach to this problem. We define three conditions as essential to ensure the viability of a profit allocation: efficiency, individual rationality and coalition rationality. From this point on, a solution for the profit allocation problem based on the concept of nucleolus has been developed. It allows us to design a robust mechanism for the distribution of the surplus generated by collaboration, which takes into account the bargaining power of the different nodes. This solution is aimed at maximizing the minimum happiness of the possible coalitions and consequently at ensuring the stability and sustainability of long term coalitions.

Please note that an underlying assumption of this game-theoretical approach is that the net profit of each node would be the same if the node does not cooperate, regardless of how the other supply chain members behave. This condition would not apply in some real-world supply chain scenarios, where the different nodes are seriously impacted by the decisions of their partners. Under these circumstances, we plan the development of a mechanism that takes this fact into consideration as a potential and interesting next step.

\section{References}

Costas, J., Ponte, B., de la Fuente Fuente, D., Pino, R., \& Puche, J. (2015). Applying Goldratt's Theory of Constraints to reduce the Bullwhip Effect through agent-based modeling. Expert Systems with Applications, 42(4), 2049-2060. https:/doi.org/10.1016/j.eswa.2014.10.022 
Fawcett, S.E., McCarter, M.W., Fawcett, A.M., Webb, G.S., \& Magnan, G.M. (2015). Why supply chain collaboration fails: the socio-structural view of resistance to relational strategies. Supply Chain Management: An International Journal, 20(6), 648-663. https:/doi.org/10.1108/SCM-08-2015-0331

Fliedner, G. (2003). CPFR: an emerging supply chain tool. Industrial Management \& data systems, 103(1), 14-21. https:/doi.org/10.1108/02635570310456850

Goodwin, J.S., \& Franklin, S.G. (1994). The beer distribution game: using simulation to teach systems thinking. Journal of Management Development, 13(8), 7-15. https:/doi.org/10.1108/02621719410071937

Hartman, B.C., \& Dror, M. (1996). Cost allocation in continuous-review inventory models. Naval Research Logistics, 43(4), 549-561. https:/doi.org/10.1002/(SICI)1520-6750(199606)43:4<549::AID-NAV7>3.0.CO;2-7

Jarmain, W.E. (1963). Problems in industrial dynamics. Cambridge: Mit Press.

Leng, M., \& Parlar, M. (2009). Allocation of cost savings in a three-level supply chain with demand information sharing: A cooperative-game approach. Operations Research, 57(1), 200-213. https:/doi.org/10.1287/opre.1080.0528

Lozano, S., Moreno, P., Adenso-Díaz, B., \& Algaba, E. (2013). Cooperative game theory approach to allocating benefits of horizontal cooperation. European Journal of Operational Research, 229(2), 444-452. https:/doi.org/10.1016/j.ejor.2013.02.034

Nagarajan, M., \& Sošić, G. (2008). Game-theoretic analysis of cooperation among supply chain agents: Review and extensions. European Journal of Operational Research, 187(3), 719-745.

https:/doi.org/10.1016/j.ejor.2006.05.045

Ponte, B., Costas, J., Puche, J., de la Fuente, D., \& Pino, R. (2016). Holism versus reductionism in supply chain management: An economic analysis. Decision Support Systems, 86, 83-94.

https:/doi.org/10.1016/j.dss.2016.03.010

Ponte, B., Pino, R., \& de la Fuente, D. (2014). Multiagent Methodology to Reduce the Bullwhip Effect in a Supply Chain. In Transactions on Computational Collective Intelligence XVII (1-21). Springer Berlin Heidelberg. https:/doi.org/10.1007/978-3-662-44994-3_1

Puche, J., Ponte, B., Costas, J., Pino, R., \& de la Fuente, D. (2016). Systemic approach to supply chain management through the viable system model and the theory of constraints. Production Planning \& Control, 27(5), 421-430. https:/doi.org/10.1080/09537287.2015.1132349 
Saad, W., Han, Z., Debbah, M., Hjorungnes, A., \& Basar, T. (2009). Coalitional game theory for communication networks. IEEE Signal Processing Magazine, 26(5), 77-97.

https:/doi.org/10.1109/MSP.2009.000000

Schmeidler, D. (1969). The nucleolus of a characteristic function game. SIAM Journal on Applied Mathematics, 17(6), 1163-1170. https:/doi.org/10.1137/0117107

Simatupang, T.M., \& Sridharan, R. (2002). The collaborative supply chain. The International Journal of Logistics Management, 13(1), 15-30. https:/doi.org/10.1108/09574090210806333

Simatupang, T.M., \& Sridharan, R. (2005). The collaboration index: a measure for supply chain collaboration. International Journal of Physical Distribution \& Logistics Management, 35(1), 44-62. https:/doi.org/10.1108/09600030510577421

Simatupang, T.M., \& Sridharan, R. (2007). The architecture of supply chain collaboration. International Journal of Value Chain Management, 1(3), 304-323. https:/doi.org/10.1504/IJVCM.2007.013306

Simatupang, T.M., \& Sridharan, R. (2008). Design for supply chain collaboration. Business Process Management Journal, 14(3), 401-418. https:/doi.org/10.1108/14637150810876698

Sterman, J.D. (1989). Misperceptions of feedback in dynamic decision making. Organizational Behavior and Human Decision Processes, 43(3), 301-335. https:/doi.org/10.1016/0749-5978(89)90041-1

Waller, M., Johnson, M.E., \& Davis, T. (1999). Vendor-managed inventory in the retail supply chain. Journal of Business Logistics, 20(1), 183.

Wang, X., \& Disney, S.M. (2016). The bullwhip effect: Progress, trends and directions. European Journal of Operational Research, 250(3), 691-701. https:/doi.org/10.1016/j.ejor.2015.07.022

Wood, A. (1993). Efficient consumer response. Logistics Information Management, 6(4), 38-40. https:/doi.org/10.1108/EUM0000000002908

Journal of Industrial Engineering and Management, 2016 (www.jiem.org)

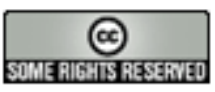

Article's contents are provided on an Attribution-Non Commercial 3.0 Creative commons license. Readers are allowed to copy, distribute and communicate article's contents, provided the author's and Journal of Industrial Engineering and Management's names are included. It must not be used for commercial purposes. To see the complete license contents, please visit http://creativecommons.org/licenses/by-nc/3.0/. 